\title{
The Relationship between Language, Literature, Teacher Effectiveness and Quality Education
}

\author{
Amase, Lanior Emmanuel PhD (Corresponding author) \\ Department of Language and Communication Studies, Federal University Dutsinma \\ Katsina State, Nigeria
}

Tel: 234-703-128-6205. E-mail: eamase@fudutsinma.edu.ng

Tsavmbu, Aondover Alexis

Department of Language and Communication Studies, Federal University Dutsinma

Katsina State, Nigeria

Tel: 234-803-468-9676. E-mail: atsavmbu@fudutsinma.edu.ng

Kaan, Aondover Theophilus

Department of Language and Communication Studies, Federal University Dutsinma

Katsina State, Nigeria

Tel: 234-706-902-1900. E-mail: akaan@fudutsinma.edu.ng

Received: July 26, 2013 Accepted: September 24, 2013 Published: November 28, 2013

doi:10.5296/ijssr.v2i1.4633

URL: http://dx.doi.org/10.5296/ijssr.v2i1.4633

\begin{abstract}
The issue of declining quality of education in Nigeria is of serious national concern and quality language education is not an exception. A wide range of factors have been pointed out by experts as being responsible for this situation. Our purpose in this paper is to discuss possible ways of improving on the quality of language education being that the quality of an educational system cannot transcend that of the teachers. The paper contends that for quality language education to be provided, the teacher must be effective; he must be well grounded in both language and literature to effectively impart quality language education. The paper examines the interwoven relationship between language and literature and postulates that merely having many years of classroom experience does not automatically make one an effective teacher. It also discusses several other methods that could be adopted in teaching so as to improve on the quality of language education being provided. The paper concludes that the delicate relationship between language, literature and effective teaching must be
\end{abstract}


sufficiently appreciated by the language teacher in order for the objectives of language course to be attained.

Keywords: Language, literature, quality education, teacher effectiveness, improvement, development

\section{Introduction}

We believe that this topic is apt as it has the potential for addressing the decline in the quality of education in Nigeria, which is an issue of serious national concern. Whether or not there is indeed decline is not the main issue here; our purpose is to fulfill one of the requirements of academics: to brainstorm and better position the academia to improve on the quality of education provided to students at all levels; conscious of the fact that the quality of an educational system cannot transcend that of the teachers, hence the necessity for teachers to continually seek avenues for self development by either creating or availing themselves of such opportunities as the one made available in this write-up.

Our task here is quite a simple one: to trigger off a healthy discourse by those involved in language education at all levels for our mutual benefit as language teachers and better position ourselves to discharge the onerous responsibility of providing quality education to students placed under our care.

It could be observed that there is a clear link among the key concepts in the title of this paper - language, literature, teacher effectiveness and quality education. However, we must concede that "teacher effectiveness" and "quality education" are rather too open-ended for the scope we intend to cover in this paper. Therefore, we shall narrow the discussion down to "teacher effectiveness" and "quality education" in the context of language hence our preference for "quality (language) education". Our position is that "quality (language) education" is that which successfully speaks to the aims and objectives that informed the setting up of the language course in the first place. Our contention is also that for "quality (language) education" to be provided, the teacher must be effective and this is where the relationship between language and literature is not merely important but critical. We have made bold to say that the relationship between language and literature is too inextricably interwoven for one to exist without the other. This paper posits that a teacher who wants to provide "quality (language) education" must be well grounded in both language and literature for it is only by so doing can he be effective in discharging his duties creditably.

\section{Conceptual Clarifications}

\subsection{Quality Education}

The first question that would come to probing minds is what kind of education qualifies to be designated as "Quality Education". The National Teacher's Institute believes that quality education is:

education which transcends the four walls of the classroom, one which exposes the student firstly to everything in life, both positive and negative...one which empowers him with wisdom to choose that which is right 
not because he is prejudiced into doing it, but because he is convinced that it is right (NTI 2003: 3).

However, we consider this understanding rather vague, ambitious and ambiguous, particularly the dimensions of "exposing the students firstly to everything in life, both positive and negative ...". Our objection is based on the fact that education seeks to inculcate those qualities that make an individual useful to both himself, his immediate environment and especially his nation rather than project to the learner's consciousness those negative tendencies that a people can be better off without, in the name of exposing the child "to do everything in life". Besides, it is not possible to educate a child "to do everything in life" as the definition presupposes.

That observation still leaves us with the question of what "quality education" actually is. We believe that for every educational system, there are aims and objectives and its success or otherwise is measured by the extent to which the educational system achieves such aims and objectives. It is for this reason that we strongly suggest that as language teachers at whatever level we operate, our ability to provide quality education will essentially be measured by the extent to which we groom, nurture and produce individuals who will possess the basic language skills and demonstrate that knowledge in all given language situations; for that is basically what we do as language teachers: imparting the four basic skills at whatever level we teach be it at the elementary, primary, secondary or tertiary level. As language teachers, the concept of quality education should therefore be understood in the context of achieving the overall objectives of the language course. Only by realistically envisioning our responsibility in this way, can we determine whether or not we are providing quality education.

\subsection{Teacher Effectiveness}

There is also the matter of "teacher effectiveness". What makes a teacher effective? Is it proficiency at lesson preparation, acquisition of excellent communication skills, accumulation of on the field experience, or knowledge of student learning styles? The answer to this question necessitates our understanding of who a teacher is. The answer has been provided by Smith (1969), who looks at a teacher as someone who can impart knowledge to another individual or group of individuals or one who can cause to take place a system of actions intended to induce change in behaviour in line with stated objectives. Therefore, having many years of experience, proficiency at lesson preparation, acquisition of excellent communication skills, and knowledge of student learning styles on their own do not automatically translate to expert teaching or teacher effectiveness: these qualities are useful only when the teacher continually engages in self-reflection and modifies classroom techniques to better serve the needs of students for the overall attainment of the stated aims and objectives. Teachers must prepare to teach a wide range of students in terms of interest, motivation and ability, some of whom may need additional assistance. Effective teachers assess needs, abilities, and preparedness on a class-by-class, student-by-student basis and respond to these needs accordingly. That is why Pintrich (1994) says effective teachers should: 
- Adjust their lessons based upon the needs and abilities of their students,

- Keep abreast of developments in their field or discipline and incorporate these ideas into their lessons,

- Organise the material in such a way as to best facilitate learning,

- Use effective communication skills

- Formulate specific goals and objectives and then select the best methods for meeting those objectives,

- Share the course objectives with the students to clarify expectations for the students and open communication,

- Work to build rapport with their students,

- Establish a productive learning atmosphere, and

- Use effective communication skills. (Pintrich 1994:23 - 43)

Though the requirements for effective teaching have been lucidly pointed out immediately above, we have to agree with O'Neill (2013) that teaching is so complex a craft that in some ways, "it is impossible to capture in a page or two the sophistication of what effective teachers do" (O’Neill, 2013:1). However, nothing is more fundamental to achieving our goal of success for every student than effective or high quality teaching as envisioned above. That is why a classroom first places the teacher at the centre of improvement efforts. It is important for all teachers in our schools to have a clear understanding of the department's position in relation to effective teaching practice for the attainment of quality education.

\subsection{Language}

Perhaps of more importance in the matrix of "Teacher Effectiveness" and "Quality Education" is "Language". It will be presumptuous to believe that one can give an accurate definition of language. Some definitions foreground their limitations by their inclusion of not only the significant characteristics of language but also some of the controversies about its nature. For instance Finnegan (2012) views language, “... as a vehicle of thought, a system of expression that mediates the transfer of thought from one person to another" (Finnegan, 2012: 6). Playing a slightly different tune, Finocchario defines language as, "a system of arbitrary, vocal symbols which permit all people in a given culture or other people who have learned the system of that culture, to communicate or interact" (Finocchario, 1964:8). However, if language is understood merely as a system of communication, as Finnegan implies, or as the ability to produce speech sounds as conceived by Finocchario (1964), then language is not unique to humans because there is proof that animals too do communicate via the use of sounds. Such a position would contradict that of Fromkin et al. (2011: 26) who have sufficiently convinced us that "language is species specific" to the humans because there are certain characteristics of human language not found in the communication systems of animals, the most fundamental being the creative potential of human language. It is this creativity that gives human beings the 
ability to combine the basic linguistic units to form an infinite set of grammatical sentences, most of which may be novel.

The point of the above is not to advertise the perceived weakness of the two positions on language considered above; rather, it is to impress on our consciousness the near impossibility of providing an accurate definition of language. For our purpose in this discussion therefore, we shall draw inspiration from Saussure's insight that, "human language is a system of signs" as quoted by McGregor (2009:8). This means that human language is made of signs, which rather than operate in isolation, interrelate and form a system that is understood by members of the given speech community who are able to use that system to form an infinite set of grammatical sentences that are understood by others in the same language community. That is why when you know a language, you can speak and be understood by others who know that language. This means you have the capacity to produce sounds that signify certain meanings and to understand or interpret the sounds produced by others despite the absence of a one to one relationship between signs and what they represent. It is this ability that humanizes man (and woman) and distinguishes him from other animals. Fromkin et al. (2011), posit:

... according to the philosophy expressed in the myths and religions of many people of Africa, a newborn child is a kintu, a "thing", not yet a mantu, a "person". Only by the act of learning language does the child become a human being. According to this tradition, we all become "human" because we all know at least one language (Fromkin et al., 2011: 284).

Our humanity is therefore defined by our ability to use language hence language remains an indispensible attribute of humanity.

\subsection{Literature}

Finally among the key concepts we are considering is that of literature. Just like language, the quest for an acceptable definition of literature is an age old one, though the conclusions are seldom satisfactory. Most definitions of literature are so broad and vague that they are not acceptable; an example is that which says "literature is anything written down" (NOUN, 2009: 16). Other definitions that may be accepted at one time do change with time. In fact, the only inevitable thing about defining literature is that the definition will change since what is considered literary genius in one generation may be seen as ordinary and not worthy of comment in another generation.

For instance, one can define literature as 'imaginative' writing in the sense of fiction by which is meant writing that is not literally true (Eagleton, 2013). But even the briefest reflection on what people commonly include under the heading 'literature' suggests that this will not do. This is because seventeenth century English literature includes essays and sermons as well as spiritual autobiographies that do not qualify to be called 'imaginative' writing. Consequently, a distinction between 'fact' and 'fiction' presupposed in that definition is unlikely to get us very far, not least because the distinction itself is often a questionable one particularly in this world where many people believe that truth is relative to either circumstances or personalities involved. 
What should therefore, be of paramount concern to us in our attempt to define literature should be the manner of presentation of a work; what we call the "How" and not the "What" of a write up. That is why Widdowshon (1975) believes that the understanding that the study of literature is fundamentally a study of language in operation is based on the realisation that literature is an example of language in use, and is a context for language use. This is to say works of literature thrive on the ability of the writer to play with the words, turning them into raw materials for the display of creative ingenuity. This is why some scholars favour the view by the Russian critic known as Roman Jacobson according to whom literature represents 'organised violence committed on ordinary speech' (Eagleton, 2013: 1). This means that when one uses language in a manner which does not conform to the dictates of normal speech, he is in the realm of literature. Works of literature tell stories that mirror real life situations to advocate ideas and express emotions or feelings. As we read literature, we learn more about the world around us while at the same time we enjoy the stories presented.

\section{The Relationship between Language, Literature, Teacher Effectiveness and Quality Education}

Language, literature, teacher effectiveness and quality (language) education are related and in fact inextricably interwoven concepts. This is because an ineffective language teacher cannot provide quality education but it is not possible for a language teacher to be effective if he is not well grounded in both the language he teaches and the literature that emanates there-from. This is because language and literature are two sides of the same coin such that it is hard to say which of the two takes precedence over the other. Their relationship is just like that between a chicken and an egg: without an egg you cannot have a chicken yet it is the chick that grows to lay eggs. Welleck and Warren (1970: 22) have succinctly captured this relationship when they say, "Language is the material of literature as stone or bronze is of sculpture, paints of picture, or sounds of music" implying that whereas language is a system of communication, literature is the content being communicated. The question of one being superior to the other cannot arise because both are complementary as they enrich and glorify each other. That is why a successful language teacher must be highly proficient in both, to provide quality education. That is also why a background of literature is a necessary precondition for prospective language students and especially for those seeking to teach language at all levels of our education. Several classroom situations vindicate this position as we shall see shortly:

First and foremost, "quality (language) education" requires that students be nurtured to acquire and sustain a rich repertoire of words that enables them to explore the creative potentials of language in all ramifications. Language students that go through a goal oriented language course are exposed to literature that enriches their vocabulary and by so doing release themselves from the claws of dictionaries. This empowers them with sufficient creative acumen to generate not just an infinite number of words but more importantly an expansive range of quality sentences; thus, widening their communicative efficacy. This is important because according to Fromkin et al. (2011), it is the creative nature of human language that marks human language out from that used by animals. To achieve this however, the teacher must carefully select literature texts he chooses to expose the students to and 
insist that they read all with a pen and jotter; ready to jot all new words and sentence structures they encounter for discussion later in the classroom. This way, the teacher ensures that a very rich quantum of words and sentences are made available for study after every literature class.

Secondly, for many students in a language class, literature motivates them to read based on the interesting plots. We can cast our minds back to those years when we used to read the action packed novels of James Hardley Chase, or James Bond or the Mills and Boom series. At the time, the main motivation would be the thrill that the content provided but every language teacher knows that apart from the stories, the works themselves are ideal vehicles for demonstrating language use: The various syntactic structures we scrupulously teach during language lessons, the tedious and sometimes grueling lessons on lexis and structures, the painstaking efforts we expend on registers as well as the exhausting inroads we make into idiomatic expressions etc will not amount to much without avenues of practical demonstration. The success, of course, in using literature for the attainment of this objective depends largely on the selection of texts which will not be difficult on either the linguistic or conceptual level. Good choice of texts not only helps to bring all language lessons to life but also shows how language should be used in contexts.

Thirdly, we had already pointed out during our discussion on effective language teaching that what we do in language classes is to develop and sustain the basic skills of listening, speaking, reading and writing and this is where literature becomes indispensable. It helps students not only to learn and improve their reading but also their listening, speaking and writing through the series of texts they are exposed to. However, success cannot be attainable in this regard unless the class is made as participatory and as student centred as possible. This is because listening, speaking, reading and writing skills cannot be developed through teacher centred approaches that make students passive participants.

Furthermore, through literature, learners are exposed to experiences and events in real life which expose people to a spectrum of real life experiences that exert varying demands on language and their language competence. Learners for instance appreciate the fact that being proficient in English language, necessarily requires not only being able to acquire but more importantly delineate the varieties of English language to be used from the existing "Englishes" as dictated by the exigencies of the language situations they may find themselves in. When for instance learners read and analyse Chinua Achebe's Anthills of the Savannah and are led through a systematic analysis of its narrative techniques, particularly language use, they will understand why the major characters in the novel such as Chris Oriko, Ikem Osodi, Sam, and particularly Beatrice code switch seamlessly from Queen's English to Nigerian English and then to pidgin despite the fact that they are graduates of famous British universities. Understanding the dynamics that occasion such fluid and effortless transition from one variety of English to another in the novel will expedite students' language acquisition skills particularly as regards equipping them to select from the multiplicity of varieties that preponderate the Nigerian English community. 
Moreover, one of the key challenges of teaching English language in Nigeria is the exigency of dealing with mother tongue interference that exists not merely at the phonological level as many people believe but also at the lexical, syntactic and semantic levels. The situation is becoming so mixed up that the English language has not only acquired a distinct Nigerian colouration but is also fast developing unique ethnic identities such that it is now possible to talk of Igbo English, Tiv English, Hausa English and Yoruba English etc. Although this is a natural consequence of language in contact situation, we as teachers of English language must bear in mind the following facts: first, that what we teach or rather should teach is the standard Queen's English. And secondly, we should not lose sight of the fact that majority of those who speak these 'Nigerian varieties' of English language are completely ignorant of that fact; that is why some may be genuinely offended when you label their brand of English as such. The potential of literature for containing this challenge is unprecedented. Through careful selection, study and analysis of texts such as Amos Tutuola's The Palm wine Drinkard (1952), My Life in the Bush of Ghosts (1952), Simbi and the Satyr of the Dark Jungle (1955) Ajaiye and His Inherited Poverty (1968), The Brave African Huntress (1958), The Witch Herbalist of the Remote Town (1981) and even Chinua Achebe's Things Fall Apart etc, learners of English will realise that a good deal of what they take for granted as standard English expressions merely exemplify all manner of interferences from their mother tongues. The positive multiplier effect of such realisation on the study of English language can only be imagined.

Related to the above is the fact that it is language that gives the literature of any people its peculiarities; giving it a unique identity. For instance, one of the distinguishing features of Nigerian literature is not only the abundance of Nigerian proverbs, idiomatic expressions and figures of speech, but also transferred lexical items used in the Nigerian environment.

In Achebe's works, for instance, he uses many indigenous words such as nza, ogene, Afo, Nkwo, Eke, Iroko, Nzu, etc which have no English equivalents, to express Nigerian concepts. If he had translated these word's into English, they might not have carried the proper degree of solemnity or implied a sufficient sense of the reverence in which such words are held by the local audience. Thus, the peculiarity of Nigerian literature in English is that it is produced in the Nigerian variety of English language known as Nigerian English .... Indeed, it is the use of language that distinguishes African literature from British or American literature, for instance, in spite of the fact that they are all produced in English language (Abugu, 2010: 2).

This shows that through literature, it is possible to use language and make valid statements that promote not only cultural but national pride as Achebe and quite a few African writers have successfully done in their works.

In addition, according to O'Neil (2013:1), “effective teachers also understand that students learn best if their particular culture, background and abilities are acknowleidged by the teacher in the way they teach". This fact becomes very critical in a multicultural and multi-religious setting like Nigeria in which even the slightest disregard of this injunction can bring about 
grave consequences ranging from total loss of interest in the lesson to outright outbreak of social conflagrations that may engulf not just the institution and immediate community in question but the nation at large - in either case, the objectives of the language class in question shall have been irreparably compromised. An instance that comes readily to mind is where a language teacher, in his attempt to teach the history of English language and literature to a predominantly Muslim class, chooses George Eliot's poem entitled "The Journey of the Magi" to exemplify the Romantic period. Such a teacher may inadvertently alienate the predominantly Muslim students who may misconstrue his choice of the poem as a calculated attempt to expose them to Christianity with the intention of converting them to the faith. However, when the literature material that is selected takes into cognizance the background of the students, both cultural and religious, the learners will be more favourably disposed to the lesson thus enhancing chances of success.

\section{Conclusion}

From the foregoing, it is clear that nothing can be more self restraining than entertaining the illusion of "effective (language) teaching" without literature because literature affords language learners the opportunity to learn how language works in real contexts. A language course without literature is just like a science course bereft of practical sessions. Similarly, there cannot be literature without language and herein lies the dilemma of a language teacher or learner that fails to sufficiently appreciate this delicate relationship. However, a language teacher who appreciates this relationship will be quite effective in his job and provide "Quality (language) education".

\section{References}

Abugu, B. (2010). Literature as the Manipulation of Language for Creative Purposes. In Experts Column. Retrieved April 5, 2010, from http://expertscolumn.com

Edward, F. (2012). Language Its Structure and Use (6th Ed.). United States of America: Wadworth Cengage Learning.

Finocchario, M. B. (1964). Language Learning and Teaching. Retrieved September 13, 2013, from www.literature.freeservers.com

National Teacher's Institute. (2000). NCE/DLS Course Book on English Language: Cycle 3, Kaduna: National Teacher's Institute (NTI).

National Open University of Nigeria (NOUN). (2009). Course Guide on Introduction to English Literature 1. National Open University of Nigeria Headquarters, 14/16 Ahmadu Bello Way, Victoria Island, Lagos.

Othaniel, B. S. (1969). A concept of teaching. In C. J. C. Macmillan \& W. N. Thomas (Eds.), Concepts of Teaching Philosophical Essays. Chicago: Rand Monally and Coy.

Pintrich, P. R. (1994). Student Motivation in the College Classroom. In K. W. Pritchard \& R. McLaren Sawyer (Eds.), Handbook of College Teaching: Theory and Applications (pp. 23-43). Westport, CT: Greenwood Press. 
Rene, W., \& Austin, W. (1970). Theory of Literature. Harmands-Worth: Penguin Books.

Sharyn, O’Neill. (2013). Effective Teaching. A publication of the Department of Education and Training. Retrieved June 12, 2013, from http://www.education.com

Terry, E. (2013). Introduction: What is Literature? Retrieved June 10, 2013, from www.dartmuth.edu

Victoria, F., Robert, R., \& Nina, H. (2011). An Introduction to Language (9th Ed.). Canada: Wadsworth, Cengage Learning.

Widdowson, H. G. (1975). Stylistics and the Teaching of Literature. London: Longman.

William B. McGregor. (2009). Linguistics: An Introduction. London: Continuum International Publishing Group.

\section{Copyright Disclaimer}

Copyright reserved by the author(s).

This article is an open-access article distributed under the terms and conditions of the Creative Commons Attribution license (http://creativecommons.org/licenses/by/3.0/). 